\title{
Studi validasi indeks massa tubuh dan rasio lingkar pinggang panggul terhadap profil lipid pada pasien rawat jalan di Poli Jantung RSUP Dr. Sardjito Yogyakarta
}

Tenta Septina ${ }^{1}$, Martalena Purba², Yayuk Hartriyanti ${ }^{3}$

\begin{abstract}
Background: Obesity is one of nutrition status categories that can be measured with various methods, just like nutrition status. So far, anthropometric methods such as body mass index (BMI) and Waist-to-Hip Ratio (WHR) are commonly used due to their practicality and inexpensiveness. However, biochemical examination will give more objective result, apart from its ability to make early detection of body changes. Lipid profile is a biochemical method that can be used to predict excess of fat deposit (hyperlipidemia) that causes obesity.

Objective: To identify validity of BMI and WHR compared to lipid profile of out-patient at cardiology clinic of Dr. Sardjito Hospital.

Method: The study was observational with cross sectional design undertaken at cardiology clinic of Dr. Sardjito Hospital Yogyakarta. Samples were patients of over 40 years old that had blood lipid profile whose height, weight, waist and hip circumference could be measured and were willing to participate. Patients on wheel chair or unable to stand up properly and wearing tight clothes were excluded. Sensitivity and specificity test was made to assess the validity of BMI and WHR against lipid profile.

Result: As many as 52 samples (53.6\%) had hypercholesterolimia, 45 (46.4\%) had normocholesterolemia. As many as 38 samples (39.2\%) had hypertrygliceridemia, 59 (60.8\%) had normotrygliceridemia. Based on BMI 76 samples (78.3\%) were obese and 21 (21.7\%) non obese. Based on WHR as many as 79 samples (81.5\%) were of central obese and 18 (18.5\%) non obese. Sensitivity of BMI and WHR was good but their specificity was low.

Conclusion: BMI and WHR could be used to detect hypercholesterolemia and hypertrygliceridemia due to their good sensitivity; but they could not be used to predict normocholesterolemia and normotrygliceridemia due to their low specificity.
\end{abstract}

KEY WORDS lipid, body mass index, waist to hip ratio, obesity, sensitivity, specificity

\section{PENDAHULUAN}

Seiring dengan meningkatnya taraf kesejahteraan masyarakat, jumlah kasus obesitas cenderung meningkat (1). Obesitas merupakan faktor risiko terjadinya berbagai penyakit degeneratif seperti diabetes, penyakit jantung dan kardiovaskular (2). Banyak faktor yang memicu terjadinya obesitas, seperti peningkatan pendapatan masyarakat, perubahan pola makan menjadi tinggi kalori dan lemak serta rendah serat, dan perubahan pola aktivitas masyarakat yang menjadi semakin berkurang (1).

Penilaian status gizi dapat dilakukan sebagai langkah awal dalam pendeteksian obesitas dan faktor yang terkait. Terdapat dua cara penilaian status gizi, yaitu secara langsung yang meliputi antropometri, biokimia, klinis, fisik dan tidak langsung yang terdiri dari survei konsumsi makanan dan faktor ekologi (3).

Antropometri merupakan indikator yang telah lama dan sering digunakan dalam penentuan status gizi. Indeks antropometri yang biasa digunakan untuk mendeteksi obesitas antara lain Indeks Massa Tubuh (IMT) dan Rasio Lingkar Pinggang-Panggul (RLPP). Penilaiannya mudah dilakukan sehingga sering dicantumkan dalam semua macam penilaian gizi (4).
Rasio lingkar pinggang-panggul merupakan suatu indikasi adanya obesitas sentral/android atau juga disebut obesitas abdominal. Obesitas ini erat kaitannya dengan meningkatnya risiko penyakit jantung koroner (PJK), hipertensi, dan diabetes mellitus (DM) (5).

Selain antropometri, terdapat metode biokimia yang dapat digunakan untuk menilai status gizi (4). Dalam kasus obesitas, abnormalitas lipid darah dapat menjadi indikasi adanya akumulasi lemak dalam tubuh (6). Salah satu keuntungan uji biokimia adalah dapat memberikan informasi akurat mengenai status gizi dan perubahan-perubahan dalam tubuh sebelum terjadinya perubahan klinis dan antropometri (7). Akan tetapi, pemeriksaan biokimia hanya dapat diperoleh di rumah sakit atau pusat kesehatan. Keadaan tersebut membuat penduduk yang tinggal di banyak daerah pedesaan sulit menjangkaunya (4).

\footnotetext{
Puskesmas Mergangsan, Jl. Kolonel Soegiono 98 Yogyakarta, e-mail: ta2_gmu@yahoo.com

2 Instalasi Gizi RSUP Dr. Sardjito/Program Studi Gizi Kesehatan FK UGM, e-mail:martalenap@yahoo.com.au

3 Program Studi Gizi Kesehatan Fakultas Kedokteran UGM. e-mail: uke_yh@yahoo.com
} 
Pada intinya, penilaian status gizi dilakukan untuk mengetahui apakah anatomi dan fungsi-fungsi dalam tubuh berjalan dengan baik. Baik cara antropometri maupun biokimia, akan terdapat perbedaan terhadap nilai batas normal dan interpretasinya. Perbedaan tersebut dapat menimbulkan pertanyaan lebih jauh tentang metode manakah yang paling baik untuk mendeteksi obesitas.

Pada penelitian di Puskesmas Mergangsan Yogyakarta yang mengangkat variabel pola makan, RLPP sebagai indeks status gizi, dan tekanan darah dibuktikan bahwa terdapat hubungan yang signifikan antara RLPP dengan tekanan darah dan pola makan. Penelitian tersebut menyimpulkan bahwa semakin tinggi RLPP, maka tekanan darah cenderung meningkat. Berdasarkan hasil tersebut dapat diketahui bahwa RLPP merupakan indeks yang baik untuk mendeteksi hipertensi (5).

Berdasarkan latar belakang di atas, maka timbul pertanyaan seberapa besarkah tingkat validitas indeks massa tubuh dan rasio lingkar pinggang-panggul terhadap profil lipid. Penelitian ini bertujuan untuk mengetahui tingkat validitas indeks massa tubuh dan rasio lingkar pinggang-panggul terhadap profil lipid pada pasien rawat jalan di Poli Jantung RSUP Dr. Sardjito Yogyakarta.

\section{BAHAN DAN METODE}

Jenis penelitian yang dilakukan adalah penelitian observasional dengan desain cross sectional. Penelitian dilakukan pada bulan Agustus-Oktober 2007 dengan lokasi di Poli Jantung (Poliklinik Kardiologi) RSUP Dr. Sardjito Yogyakarta.

Populasi dan sampel penelitian adalah pasien rawat jalan di Poli Jantung RSUP Dr. Sardjito. Sampel penelitian diambil berdasarkan kriteria inklusi, yaitu berusia 40 tahun ke atas, dapat ditimbang berat badan, diukur tinggi badan, lingkar pinggang, dan lingkar panggulnya, mempunyai data lipid darah (Kolesterol Total, LDL, HDL, Trigliserida) 3 bulan terakhir, bersedia berpartisipasi, dan tidak bungkuk. Kriteria eksklusi penelitian adalah sampel tidak dapat berdiri atau duduk di kursi roda dan memakai pakaian ketat. Jumlah sampel penelitian sebanyak 97 orang yang dihitung berdasarkan rumus pendugaan proporsi populasi satu sampel. Jumlah sampel sama dengan $Z \alpha$ tingkat kemaknaan sebesar $95 \%(1,96)$, nilai proporsi (P) sebesar 0,5 dan nilai d (tingkat ketepatan absolut) sebesar 0,1 (8).

Jenis data primer dan data sekunder. Data primer meliputi data lingkar pinggang, lingkar panggul, tinggi badan dan berat badan. Data antropometri dikumpulkan dengan pengukuran langsung. Kemudian data sekunder yang dikumpulkan meliputi identitas sampel, gambaran umum lokasi penelitian, dan lipid darah. Data identitas subjek dan kadar lipid darah diperoleh dari catatan medik pasien.

Variabel penelitian meliputi variabel bebas yang terdiri dari Indeks Massa Tubuh dan Rasio Lingkar Pinggang Panggul dan variabel terikat, yaitu profil lipid. Pengolahan dan analisis data meliputi penghitungan IMT, RLPP, dan profil lipid yang kemudian dimasukkan ke dalam kategori yang telah ditentukan. Batas IMT adalah 23 untuk kategori obes, di bawah 23 adalah nonobes. Batas RLPP untuk pria adalah $>0,9$ tergolong obes sentral dan pada wanita adalah $>0,8(9)$. Untuk profil lipid, yang akan dianalisis adalah data kolesterol total dengan batas normal $200 \mathrm{mg} /$ $\mathrm{dl}$, dan trigliserida dengan batas normal $150 \mathrm{mg} / \mathrm{dl}$ (10). Analisis sensitifitas (Se) dan spesifitas (Sp) IMT dan RLPP dilakukan dengan membuat tabel silang di mana profil lipid digunakan sebagai penguji (gold standard), sedangkan RLPP dan IMT adalah variabel yang diuji, seperti terlihat pada Tabel 1.

TABEL 1. Analisis sensitivitas dan spesifisitas

\begin{tabular}{lcc}
\hline & Lipid (+) & Lipid (-) \\
\hline IMT/RLPP (+) & $\mathrm{A}$ & $\mathrm{B}$ \\
IMT/RLPP (-) & $\mathrm{C}$ & $\mathrm{D}$ \\
Total & $\mathrm{A}+\mathrm{C}$ & $\mathrm{B}+\mathrm{D}$ \\
\hline
\end{tabular}

Keterangan:

$A=$ true positive (hasil pengukuran IMT/RLPP tergolong obes dan kadar lipid di atas normal)

$B=$ false positive (hasil pengukuran IMT/RLPP normal, tetapi kadar lipid di atas normal)

$\mathrm{C}=$ false negative (hasil pengukuran IMT/RLPP obes, tetapi kadar lipid normal)

$\mathrm{D}=$ true negative (hasil pengukuran IMT/RLPP normal dan kadar lipid normal)

Tingkat sensitivitas dan spesifisitas dihitung sebagai berikut: $S e=(A / A+C) \times 100 \%$ dan $S p=(S / B+D) \times 100 \%$. Hasilnya kemudian dimasukkan ke dalam kategori sebagai berikut: Amat baik : Se dan Sp > 90\%, Baik : 70\% > Se dan Sp $<90 \%$, Cukup baik : $60 \%>$ Se dan Sp $<70 \%$, Kurang baik : Se dan $\mathrm{Sp}<60 \%$ (11). Uji sensitivitas dan spesifisitas yang baik akan menghasilkan nilai false positive dan false negative yang rendah. Hal ini berarti bahwa tingkat sensitivitas dan spesifisitasnya tinggi (12).

\section{HASIL DAN BAHASAN}

\section{Karakteristik sampel}

Selama penelitian diperoleh sampel sebanyak 97 orang. Pengelompokan sampel dikategorikan atas jenis kelamin dan umur. Lebih jelasnya tentang karakteristik sampel dapat dilihat pada Tabel 2. 
TABEL 2. Distribusi jumlah sampel berdasarkan jenis kelamin dan kelompok umur

\begin{tabular}{lcc}
\hline \multirow{2}{*}{ Variabel } & \multicolumn{2}{c}{ Jumlah } \\
\cline { 2 - 3 } & $\mathbf{n}$ & $\%$ \\
\hline Jenis kelamin & & \\
$\quad$ Pria & 67 & 69,0 \\
$\quad$ Wanita & 30 & 31,0 \\
$\quad$ Total & 97 & 100 \\
Kelompok umur & & \\
$40-49$ & 16 & 16,5 \\
$50-59$ & 31 & 31,9 \\
$60-69$ & 34 & 34,5 \\
$70-79$ & 15 & 15,5 \\
$>80$ & 1 & 1,0 \\
Total & 97 & 100 \\
\hline
\end{tabular}

Berdasarkan Tabel 2 dapat dilihat bahwa sampel yang didapat selama pelaksanaan penelitian yaitu sebanyak 97 orang, yang terdiri dari 67 orang $(69,0 \%)$ pria dan 30 orang $(31,0 \%)$ wanita, sehingga sebagian besar sampel adalah pria. Terlihat juga bahwa jumlah sampel terbanyak terdapat pada kelompok umur $60-69$ tahun, yaitu sebesar 34 orang $(34,5 \%)$.

\section{Profil lipid}

Berdasarkan hasil penelitian diketahui bahwa separuh lebih sampel mempunyai kadar kolesterol di atas normal, yaitu sebanyak 52 orang (53,6\%), sedangkan 45 orang $(46,4 \%)$ lainnya tergolong normokolesterolemia.

TABEL 3. Distribusi kolesterol total sampel berdasar jenis kelamin dan kelompok umur

\begin{tabular}{ccccc}
\hline \multirow{2}{*}{ Variabel } & \multicolumn{2}{c}{$\begin{array}{c}\text { Hiper- } \\
\text { trigliseridemia }\end{array}$} & \multicolumn{2}{c}{$\begin{array}{c}\text { Normo- } \\
\text { trigliseridemia }\end{array}$} \\
\cline { 2 - 5 } & $\mathbf{n}$ & $\%$ & $\mathbf{n}$ & $\%$ \\
\hline Jenis kelamin & & & & \\
Pria & 33 & 63,5 & 34 & 75,5 \\
Wanita & 19 & 36,5 & 11 & 24,5 \\
Total & 52 & 100 & 45 & 100 \\
Kelompok umur & & & & \\
40-49 & 8 & 15,4 & 8 & 17,7 \\
$50-59$ & 17 & 32,7 & 14 & 31,1 \\
$60-69$ & 18 & 34,6 & 15 & 33,3 \\
$70-79$ & 9 & 17,3 & 7 & 15,5 \\
$>80$ & - & - & 1 & 2,2 \\
Total & 52 & 100 & 45 & 100 \\
\hline
\end{tabular}

Tabel 3 di atas memperlihatkan bahwa dari 97 orang sampel, angka kejadian hiperkolesterolemia ternyata lebih tinggi pada wanita (19 dari 30 sampel, yang berarti dua pertiga dari jumlah sampel wanita) dibanding pria (33 dari 67 sampel, atau setengah jumlah sampel pria). Pada kelompok umur, terlihat bahwa hiperkolesterolemia cenderung lebih banyak terjadi pada kelompok umur 60-69 tahun sebanyak 18 orang $(34,6 \%)$.

Berdasarkan hasil penelitian dapat diketahui bahwa sebanyak 38 sampel $(39,2 \%)$ mempunyai kadar trigliserida yang tinggi sedangkan 59 subjek $(60,8 \%)$ lainnya dikategorikan normotrigliseridemia.

Tabel 4. Distribusi trigliserida sampel berdasarkan jenis kelamin dan kelompok umur

\begin{tabular}{|c|c|c|c|c|}
\hline \multirow[t]{2}{*}{ Variabel } & \multicolumn{2}{|c|}{$\begin{array}{c}\text { Hiper- } \\
\text { trigliseridemia }\end{array}$} & \multicolumn{2}{|c|}{$\begin{array}{c}\text { Normo- } \\
\text { trigliseridemia }\end{array}$} \\
\hline & $\mathbf{n}$ & $\%$ & $\mathbf{n}$ & $\%$ \\
\hline \multicolumn{5}{|l|}{ Jenis kelamin } \\
\hline Pria & 26 & 68,4 & 41 & 69.5 \\
\hline Wanita & 12 & 31,6 & 18 & 30,5 \\
\hline Total & 38 & 100 & 59 & 100 \\
\hline \multicolumn{5}{|c|}{ Kelompok umur } \\
\hline $40-49$ & 5 & 13,1 & 11 & 18,6 \\
\hline $50-59$ & 13 & 34,2 & 18 & 30,5 \\
\hline $60-69$ & 11 & 28,9 & 22 & 37,3 \\
\hline $70-79$ & 9 & 23,7 & 7 & 11,8 \\
\hline$>80$ & - & - & 1 & 1,7 \\
\hline Total & 38 & 100 & 59 & 100 \\
\hline
\end{tabular}

Tabel 4 di atas memperlihatkan bahwa dari 97 orang sampel, baik pria maupun wanita lebih banyak yang memiliki kadar kolesterol normal. Pada sebaran umur, hipertrigliseridemia banyak ditemukan pada rentang umur 50-59 tahun sebanyak 13 sampel $(34,2 \%)$.

\section{Indeks massa tubuh}

Dari hasil penelitian dapat diketahui sebanyak 21 $(21,6 \%)$ sampel tergolong ke dalam kategori nonobes dan $76(78,4 \%)$ orang lainnya tergolong obes.

TABEL 5. Distribusi indeks massa tubuh sampel berdasarkan jenis kelamin dan kelompok umur

\begin{tabular}{lcccc}
\hline \multirow{2}{*}{ Variabel } & \multicolumn{2}{c}{ Obes } & \multicolumn{2}{c}{ Nonobes } \\
\cline { 2 - 5 } & $\mathbf{n}$ & $\%$ & $\mathbf{n}$ & $\%$ \\
\hline Jenis kelamin & & & & \\
Pria & 51 & 67,1 & 16 & 76,2 \\
Wanita & 25 & 32,9 & 5 & 23,8 \\
$\quad$ Total & 76 & 100 & 21 & 100 \\
Kelompok umur & & & & \\
40-49 & 14 & 18,4 & 2 & 9,5 \\
$50-59$ & 26 & 34,2 & 5 & 23,8 \\
$60-69$ & 26 & 34,2 & 7 & 33,3 \\
$70-79$ & 9 & 11,8 & 7 & 33,3 \\
$>80$ & 1 & 1,3 & - & - \\
Total & 76 & 100 & 21 & 100 \\
\hline
\end{tabular}

Berdasarkan Tabel 5 terlihat bahwa sebagian besar sampel tergolong obes. Namun, kejadiannya cenderung lebih tinggi pada wanita. Pada kelompok umur, obesitas ditemukan paling banyak pada dua rentang usia, yaitu usia 50-59 tahun dan 60-69 tahun dengan jumlah 26 subjek $(34,2 \%)$.

\section{Rasio lingkar pinggang panggul}

Hasil penelitian menunjukkan bahwa sebanyak 18 $(18,5 \%)$ sampel tergolong kategori non-obes dan 79 $(81,5 \%)$ orang tergolong obes sentral. 
TABEL 6. Distribusi rasio lingkar pinggang dan panggul sampel berdasar jenis kelamin dan kelompok umur

\begin{tabular}{ccccc}
\hline \multirow{2}{*}{ Variabel } & \multicolumn{2}{c}{ Obes sentral } & \multicolumn{3}{c}{ Non-obes } \\
\cline { 2 - 5 } & $\mathbf{n}$ & $\mathbf{0}$ & $\mathbf{n}$ & $\%$ \\
\hline Jenis kelamin & & & 16 & \\
Pria & 51 & 64,5 & 2 & 11,1 \\
Wanita & 28 & 35,5 & 18 & 100 \\
Total & 79 & 100 & & \\
Kelompok umur & & & 2 & 11,1 \\
$40-49$ & 14 & 17,7 & 6 & 33,3 \\
$50-59$ & 25 & 31,6 & 6 & 33,3 \\
$60-69$ & 27 & 34,2 & 4 & - \\
$70-79$ & 12 & 15,2 & - & 100 \\
$>80$ & 1 & 1,3 & 18 & -2 \\
Total & 79 & 100 & &
\end{tabular}

Berdasarkan Tabel 6 dapat diketahui bahwa kejadian obesitas pada sampel wanita cenderung lebih tinggi prevalensinya (28 dari 30 sampel). Sedangkan pada kategori kelompok umur, kejadian obesitas sentral ditemukan paling banyak pada rentang usia 60-69 tahun sebanyak 27 pasien $(34,2 \%)$.

\section{Analisis validitas IMT dan RLPP}

\section{Analisis Sensitivitas (Se) dan Spesifisitas (Sp) IMT terhadap Profil Lipid}

Berdasarkan Tabel 7 dapat diketahui bahwa tingkat sensitivitas IMT terhadap profil lipid tergolong baik (Se>70\%), namun spesifitasnya tergolong kurang baik $(\mathrm{Sp}<60 \%)$.

Tabel 7. Hasil analisis sensitivitas dan spesifisitas IMT terhadap kolesterol total dan trigliserida

\begin{tabular}{lcccccc}
\hline \multicolumn{1}{c}{ Profil lipid } & $\begin{array}{c}\text { True } \\
(+)\end{array}$ & $\begin{array}{c}\text { False } \\
(-)\end{array}$ & $\begin{array}{c}\text { True } \\
(-)\end{array}$ & $\begin{array}{c}\text { False } \\
(+)\end{array}$ & Se & Sp \\
\hline Kolesterol total & 41 & 11 & 10 & 35 & 78,8 & 22,2 \\
Trigliserida & 34 & 4 & 17 & 42 & 89,5 & 28,8 \\
\hline
\end{tabular}

Berdasarkan Tabel 8 dapat diketahui bahwa IMT memiliki tingkat sensitivitas yang baik (Se>70\%) terhadap kedua penguji. Tetapi, tingkat spesifisitas IMT tergolong kurang baik $(\mathrm{Sp}<60 \%)$ pada kedua penguji baik sampel pria maupun sampel wanita.

Tabel 8. Hasil analisis sensitivitas dan spesifisitas IMT terhadap kolesterol total dan trigliserida berdasarkan jenis kelamin

\begin{tabular}{lcccc}
\hline & \multicolumn{2}{c}{ Pria } & \multicolumn{2}{c}{ Wanita } \\
\cline { 2 - 5 } & TC & TG & TC & TG \\
\hline True (+) & 26 & 22 & 15 & 12 \\
False (-) & 7 & 4 & 4 & - \\
True (-) & 9 & 12 & 1 & 5 \\
False (+) & 25 & 29 & 10 & 13 \\
Se (\%) & 79 & 85 & 79 & 100 \\
Sp (\%) & 27 & 30 & 9 & 28 \\
\hline
\end{tabular}

Keterangan:

$\mathrm{TC}=$ Kolesterol total

$\mathrm{TG}=$ trigliserida
Tabel 9. Hasil analisis sensitivitas dan spesifisitas IMT terhadap kolesterol total dan trigliserida berdasarkan kelompok umur

\begin{tabular}{lcccccccc}
\hline & \multicolumn{2}{c}{$\begin{array}{c}\mathbf{4 0 - 4 9} \\
\text { tahun }\end{array}$} & \multicolumn{2}{c}{$\begin{array}{c}\mathbf{5 0 - 5 9} \\
\text { tahun }\end{array}$} & \multicolumn{2}{c}{$\begin{array}{c}\mathbf{6 0 - 6 9} \\
\text { tahun }\end{array}$} & \multicolumn{2}{c}{$\begin{array}{c}\mathbf{2} \text { t0 } \\
\text { tahun }\end{array}$} \\
\cline { 2 - 9 } & TC & TG & TC & TG & TC & TG & TC & TG \\
\hline True (+) & 7 & 5 & 13 & 12 & 15 & 12 & 6 & 6 \\
False (-) & 1 & - & 4 & 1 & 3 & - & 3 & 3 \\
True (-) & 1 & 2 & 1 & 4 & 4 & 7 & 4 & 4 \\
False (+) & 7 & 10 & 13 & 13 & 11 & 14 & 3 & 3 \\
Se (\%) & 87,5 & 100 & 76,5 & 92,3 & 83,3 & 100 & 66,6 & 66,6 \\
Sp (\%) & 12,5 & 16,6 & 7,1 & 23,5 & 26,6 & 33,3 & 50 & 50 \\
\hline
\end{tabular}

Keterangan: $\mathrm{TC}=$ Kolesterol total

$\mathrm{TG}=$ trigliserida

Berdasarkan Tabel 9 dapat diketahui bahwa secara umum, sensitivisitas IMT baik namun spesifisitasnya rendah. Sensitifisitas tertinggi pada kelompok umur 40-49 tahun untuk kolesterol total $(\mathrm{Se}=87,5 \%)$, dan kelompok umur 40 49 tahun dan 60-69 tahun untuk trigliserida $(\mathrm{Se}=100 \%)$. Rendahnya tingkat spesifisitas disebabkan nilai false positive yang tinggi melebihi nilai true negative. Hal ini berarti bahwa banyak sampel yang menurut IMT tergolong obes, tetapi mempunyai profil lipid yang normal.

Penyimpangan tersebut terjadi karena sampel adalah orang sakit dan merupakan pasien kontrol yang secara rutin memeriksakan diri ke Poliklinik Kardiologi sehingga mereka telah mendapatkan pengobatan untuk menormalkan lipid mereka. Golongan obat yang biasa diberikan dokter kepada pasien ialah niacin, fibrat dan statin. Berdasarkan hasil penelitian, ternyata banyak pasien yang menerima simvastatin dari dokter.

Jellife dan Jellife (1989), dalam bukunya yang berjudul Community Nutritional Assesment telah menulis pernyataan sebagai berikut: "The advantage of some biochemical tests is that they may give information concerning nutritional status, before the appearance of clinical or anthropometry changes" (7).

Berdasarkan kutipan di atas dapat ditarik kesimpulan bahwa perubahan antropometri tidak akan terjadi secepat perubahan biokimia. Hal ini dapat diterapkan pada hasil 
analisis spesifisitas IMT terhadap profil lipid. Pemberian simvastatin dan obat-obat penurun fraksi lipid lainnya akan memberikan dampak pada penurunan lipid, dalam hal ini kolesterol dan trigliserida, namun perubahan tersebut tidak akan diiringi oleh perubahan antropometri (IMT) dengan kecepatan yang sama.

\section{Analisis sensitivitas dan spesifisitas RLPP terhadap profil lipid}

Berikut disajikan hasil analisis validitas RLPP terhadap profil lipid, baik secara umum, berdasarkan jenis kelamin, maupun berdasarkan kelompok usia.

Tabel 10. Hasil analisis sensitifitas dan spesifitas RLPP terhadap kolesterol total dan trigliserida

\begin{tabular}{lcccccc}
\hline \multicolumn{1}{c}{ Profil lipid } & $\begin{array}{c}\text { True } \\
(+)\end{array}$ & $\begin{array}{c}\text { False } \\
(-)\end{array}$ & $\begin{array}{c}\text { True } \\
(-)\end{array}$ & $\begin{array}{c}\text { False } \\
(+)\end{array}$ & Se & Sp \\
\hline Kolesterol total & 44 & 8 & 10 & 35 & 84,6 & 22,2 \\
Trigliserida & 36 & 2 & 16 & 43 & 94,7 & 27,1 \\
\hline
\end{tabular}

Berdasarkan Tabel 10 dapat diketahui bahwa tingkat sensitivitas RLPP tergolong baik (Se>70\%), namun spesifisitasnya kurang baik $(\mathrm{Sp}<60 \%)$.

Tabel 11. Hasil analisis sensitivitas dan spesifisitas RLPP terhadap kolesterol total dan trigliserida berdasarkan jenis kelamin

\begin{tabular}{lcccc}
\hline & \multicolumn{2}{c}{ Pria } & \multicolumn{2}{c}{ Wanita } \\
\cline { 2 - 5 } & TC & TG & TC & TG \\
\hline True (+) & 26 & 24 & 18 & 12 \\
False (-) & 7 & 2 & 1 & 0 \\
True (-) & 9 & 14 & 1 & 2 \\
False (+) & 25 & 27 & 10 & 16 \\
Se (\%) & 79 & 93 & 95 & 100 \\
Sp (\%) & 27 & 35 & 9 & 12 \\
\hline
\end{tabular}

Keterangan: $\mathrm{TC}=$ Kolesterol total

$$
\mathrm{TG}=\text { trigliserida }
$$

Berdasarkan Tabel 11 terlihat bahwa tingkat sensitivitas RLPP tergolong baik (Se>70\%). Pada wanita bahkan tingkat sensitivitasnya tergolong amat baik (Se>90\%), baik dengan penguji kolesterol total (Se=95\%) maupun trigliserida $(\mathrm{Se}=100 \%)$. Namun, hal ini tidak diimbangi dengan tingkat spesifisitas yang baik pula. Tingkat spesifisitas RLPP tergolong kurang baik (Sp<60\%) terhadap kedua penguji (kolesterol total dan trigliserida).

Berdasarkan Tabel 12 dapat diketahui bahwa sensitivitas RLPP tergolong baik (Se>70\%), namun sama halnya dengan IMT, spesifisitasnya tergolong rendah. Berdasar kelompok umur untuk kolesterol total, sensitivitas tertinggi berada pada kelompok umur 40 - 49 tahun. Untuk trigliserida, sensitivitas tertinggi berada pada dua kelompok umur, yaitu 40-49 tahun dan 60 - 69 tahun.
Tabel 12. Hasil analisis sensitivitas dan spesifisitas RLPP terhadap kolesterol total dan trigliserida berdasarkan kelompok umur

\begin{tabular}{lcccccccc}
\hline & \multicolumn{2}{c}{$\begin{array}{c}\mathbf{4 0 - 4 9} \\
\text { tahun }\end{array}$} & \multicolumn{2}{c}{$\begin{array}{c}\mathbf{5 0 - 5 9} \\
\text { tahun }\end{array}$} & \multicolumn{2}{c}{$\begin{array}{c}\mathbf{6 0 - 6 9} \\
\text { tahun }\end{array}$} & $\mathbf{2 7 0}$ tahun \\
\cline { 2 - 9 } & TC & TG & TC & TG & TC & TG & TC & TG \\
\hline True (+) & 8 & 5 & 13 & 12 & 15 & 12 & 8 & 8 \\
False (-) & - & - & 4 & 1 & 3 & - & 1 & 1 \\
True (-) & 2 & 2 & 2 & 5 & 3 & 6 & 3 & 3 \\
False (+) & 6 & 9 & 12 & 13 & 12 & 15 & 4 & 4 \\
Se (\%) & 100 & 100 & 76,4 & 92,3 & 83,3 & 100 & 88,88 & 88,8 \\
Sp (\%) & 25 & 18,2 & 14,3 & 27,7 & 20 & 28,5 & 37,5 & 37,5 \\
\hline
\end{tabular}

Keterangan: $\mathrm{TC}=$ Kolesterol total $\mathrm{TG}=$ trigliserida

Dari hasil analisis sensitivitas IMT dan RLPP, keduanya menunjukkan hasil sensitivitas yang baik. Namun, apabila dibandingkan dengan IMT, RLPP mempunyai tingkat sensitivitas yang lebih tinggi. Hasil ini sesuai dengan hasil penelitian Dobbelsteyn et al. di Kanada yang melibatkan 9913 pria dan wanita berusia 18 - 74 tahun. Hasil penelitian tersebut menemukan bahwa RLPP merupakan indikator yang lebih baik dibandingkan IMT untuk screening risiko penyakit kardiovaskular yang mengambil data lipid sebagai faktor risiko (9).

Beberapa hasil penelitian menunjukkan bahwa RLPP yang tinggi erat hubungannya dengan abnormalitas lipid darah. Salah satunya adalah penelitian Kohort pada Atherosclerosis Risk in Communities (ARIC) Study yang menemukan bahwa peningkatan $10 \%$ lemak tubuh akan meningkatkan kadar trigliserida sebesar $14 \%$ pada wanita dan $30 \%$ pada pria non-diabetes (13).

Pada penelitian ini yang telah dilakukan di Poliklinik Kardiologi, tingkat sensitivitas RLPP dalam mengukur obesitas pada wanita lebih tinggi apabila dibandingkan dengan IMT. Hasil ini sesuai dengan penelitian di New York yang menemukan bahwa pada wanita, RLPP yang menunjukkan obesitas sentral lebih berhubungan dengan abnormalitas lipid darah dibandingkan dengan IMT yang merupakan indeks general obesity (13).

Penelitian di Teheran (2004) menemukan hasil yang sama. Dalam penelitian yang melibatkan 4449 pria berusia 18 - 74 tahun tersebut, ditemukan bahwa RLPP merupakan indikator yang paling baik dalam screening risiko kardiovaskular-yang meliputi hipertensi, diabetes mellitus, dan dislipidemia-dibandingkan dengan indikator antropometri lainnya seperti IMT, lingkar pinggang, dan rasio lingkar pinggang per tinggi badan (14).

World Health Organization (WHO), telah menyetujui penggunaan IMT sebagai indikator obesitas pada orang dewasa. Akan tetapi, peningkatan risiko penyakit kardiovaskular ditemukan terjadi pada orang-orang yang memilki distribusi lemak yang berlebih di daerah abdominal (9). Riset di Texas, Amerika Serikat yang melibatkan 
2700 responden pria dan wanita berusia 18 - 65 tahun menemukan bahwa sedikit peningkatan pada RLPP akan meningkatkan risiko penyakit kardiovaskular bahkan dalam keadaan IMT yang normal (15).

IMT merupakan indikator general obesity, sehingga tidak menjelaskan lokasi penumpukan lemak berada. IMT lebih memprediksi kepada massa tubuh, sedangkan massa tubuh tidak hanya berisi lemak. Oleh karena itu, IMT lebih tepat dikatakan sebagai indikator overweight atau kelebihan berat badan. Lemak yang berada pada rongga abdomen justru bersifat lebih berbahaya daripada lemak yang berada di manapun dalam tubuh, seperti paha ataupun panggul. Lemak tersebut dapat menyebabkan berbagai macam komplikasi dan gangguan metabolism yang jauh lebih berbahaya (15). Oleh karena itu, pengukuran RLPP lebih tepat dilakukan untuk memprediksi adanya akumulasi lemak.

Secara umum, hasil analisis sensitivitas dan spesifisitas cara antropometri dibandingkan biokimia ini menemukan hasil bahwa pemeriksaan antropometri memiliki sensitivitas yang baik namun dengan spesifisitas kurang baik terhadap profil lipid di Poliklinik Kardiologi RSUP Dr. Sardjito. Hasil ini sesuai dengan teori yang menyatakan bahwa dibandingkan dengan cara pengukuran status gizi lain, antropometri dapat dikatakan mempunyai spesifisitas rendah, karena hampir seluruh zat gizi terlibat dalam proses pertumbuhan. Namun demikian, antropometri memiliki tingkat sensitivitas yang tinggi (16).

Dengan demikian, cara antropometri dapat digunakan untuk mengukur obesitas, khususnya indikator RLPP. Terlebih lagi karena penggunaannya sekarang semakin meluas. Selain itu, pengukuran langsung untuk menentukan kadar lemak saat ini masih terbatas karena masalah biaya, waktu, serta ketersediaan alat yang hanya ada di pusat-pusat kesehatan tertentu di wilayah tertentu. Oleh karenanya, antropometri dapat dipilih karena kemudahan pelaksanaan, sederhana dan relatif murah (17).

\section{KESIMPULAN DAN SARAN}

IMT dapat digunakan untuk mendeteksi hiperkolesterolemia dan hipertrigliseridemia tingkat sensitivitasnya baik, namun tidak dapat digunakan untuk prediksi normokolesterolemia dan normotrigliseridemia karena tingkat spesifisitasnya kurang baik.

RLPP dapat digunakan untuk mendeteksi hiperkolesterolemia dan hipertrigliseridemia karena tingkat sensitivitasnya baik, namun tidak dapat digunakan untuk prediksi normokolesterolemia dan normotrigliseridemia karena tingkat spesifisitasnya kurang baik. RLPP lebih baik dalam mendeteksi hiperkolesterolemia dan hipertrigliseridemia dibandingkan IMT karena memiliki tingkat sensitivitas yang lebih tinggi.
Perlu dilakukan penelitian lebih lanjut dengan mengeksklusi faktor-faktor yang berpengaruh seperti penyakit kronik, khususnya diabetes mellitus, dan pemakaian obat-obatan. Selain itu, penulis juga menyarankan agar dilakukan penelitian serupa dengan sampel orang sehat, sehingga berbagai risiko kardiovaskular terkait dengan penumpukan lemak dapat terdeteksi dengan lebih cepat sebelum terjadinya gangguan metabolisme dalam tubuh.

\section{RUJUKAN}

1. Ginanjar, Genis. Kegemukan dan Obesitas [serial online] 2005. Avalaible from: http:www.mailarchive. com/sma1bks@yahoogroups.com/msg01550.html.

2. Arifin Augusta. Obesitas Viseral dan Sindroma Metabolik.Prosiding Pertemuan IImiah Nasional Dietetic II;18-19 Feb 2005; Asosiasi Dietesien Indonesia Cabang Jawa Barat; 2005.

3. Supariasa, I Dewa Nyoman. Penilaian Status Gizi. Jakarta: EGC; 2001.

4. Harper, Laura. Pangan, Gizi dan Pertanian. Jakarta: UI Press; 1986.

5. Ernitasari, Putu Diah, Bambang Djarwoto dan Tri Siswati. Pola makan, Rasio Lingkar Pinggang Pinggul (RLPP) dan Tekanan Darah di Puskesmas Mergangsan Yogyakarta. Jurnal Gizi Klinik Indonesia 2009;6 (2): 71-7.

6. Baraas, Faisal. Mencegah Serangan Jantung dengan Menekan Kolesterol. Jakarta: Gramedia Pustaka Utama; 1993.

7. Jellife, Derick dan Patrice Jellife. Community Nutritional Assesment. US:Oxford University Press; 1989.

8. Sastroasmoro S. Dasar-dasar Metodologi Penelitian Klinis. Jakarta: Binarupa Aksara; 1995.

9. Dobbelsteyn, Joffres, Maclean, dan Flowerdew. A Comparative Evaluationof Waist Circumference, Waist-to-Hip Ratio and Body Mass Index as Indicators ofCardiovascular Risk Factors. International Journal of Obesity Related Metabolic Disorders 2001;25:652-61.

10. Soeharto, Iman. Kolesterol dan Lemak Jahat, Kolesterol dan Lemak Baik, dan Proses Terjadinya Serangan dan Stroke. Jakarta: PT Gramedia PustakaUtama; 2001.

11. Waspadji, Sarwono. Pengkajian Status Gizi, Studi Epidemiologi. Jakarta: FKUI; 2003.

12. Gibson, Rosalind. Principles of Nutritional Assesment. New York: Oxford University Press; 2005.

13. Hu, Dongsheng dan Judy Hannah dan Stuart Gray dan Kathleen Jablonski dan Jeffrey Henderson dan David Robbins dan Elisa Lee dan Thomas Welty dan Barbara Howard. 2000. Effects Of Obesity And Body Fat Distribution On Lipids And Lipoproteins in Nondiabetic American Indians: The Strong Heart Study. Obesity Research 2000; 8:411-21. 
14. Esmaillzadeh, Mirmiran, dan Azizi. Waistto-Hip Ratio is A BetterScreening Measure For Cardiovascular Risk Factors Than Other AntropometricIndicators In Tehranian Adult Men. International Journal of Obesity 2004; $28: 1325-$ 32.

15. Lavelle, Peter. Key to Health: Your Waist [serial online] 2007. Avalaible from: www.abc.net.au/ health/thepulse/stories/2007/08/16/2006671.html
16. Anonim. Obesitas [serial online] 2006. Avalaible from: http://www.google.com

17. Thomas, Neil dan Sai-Yin Ho dan Karen Lam dan Edward Janus dan Anthony Hedley dan Tai Hing Lam, for The Hong Kong Cardiovascular Risk Factors Prevalence Study Steering Commitee. 2004. Impact Of Obesity And Body Fat Distribution On Cardiovascular Risk Factors In Hong Kong Chinese. Obesity Research 2004;12:180513. 